\title{
Nova Previdência: o austericídio neoliberal sob a ótica da teoria marxista da dependência
}

\author{
New Social Security: neoliberal austerity under the perspective of Marxist dependence theory \\ Marcos Pereira Diligenti (1) \\ RICARDO SOUZA ARAUJO (² \\ ${ }^{1}$ Pontifícia Universidade Católica do Rio Grande do Sul, Porto Alegre, RS, Brasil. \\ ${ }^{2}$ Universidade Federal do Rio Grande do Sul, Porto Alegre, RS, Brasil.
}

RESUMO - O presente artigo propõe uma retomada às raízes da Teoria Marxista da Dependência (TMD) como vertentes do pensamento marxista dedicadas a contribuir para explicar o processo do desenvolvimento capitalista em economias dependentes, em especial, na América Latina. Valendo-se do método dialético e das categorias econômicas desenvolvidas em O Capital, Rui Mauro Marini, junto a outros autores, fundam um arcabouço teórico-explicativo para a realidade das economias periféricas, sem cair em um revisionismo simplificador. Portanto, com o intuito de aprofundar essa reflexão, apresentam-se neste trabalho, os principais conceitos da Teoria Marxista da Dependência como particularidades da reprodução do capital na América Latina. Posteriormente, utilizamos esses fundamentos interpretativos para esclarecer o austericídio verificado no Brasil hoje, no sentido de legitimar a contemporaneidade da TMD e o seu potente vetor interpretativo e transformador em tempos de crise estrutural do capital, examinando um conjunto de contrarreformas em andamento e a serem implementadas, a saber: o Novo Regime Fiscal, a Reforma Trabalhista e a "Nova Previdência".

Palavras-chave: Teoria Marxista da Dependência. Neoliberalismo. Austericídio. Brasil.

ABSTRACT - This article proposes to take up the roots of Marxist Theory of Dependence as a part of Marxist thought dedicated to explaining the process of capitalist development in dependent economies, especially in Latin America. Using the dialectical method and the economic categories developed in Capital, Rui Mauro Marini, along with other authors, found a theoretical framework that explains the reality of peripheral economies, without falling into a simplistic revisionism. In order to deepen the reflection, this paper presents the main concepts of the Marxist Theory of Dependence as particularities of the reproduction of capital in Latin America. Later we will use these interpretative foundations to clarify the current austerity in Brazil, examining the set of counter-reforms in progress and to be implemented: New Fiscal Regime, Labor Reform and the "New Social Security" in order to legitimize the contemporaneousness of TMD and its powerful vector interpretive and transformative in times of structural crisis of capital.

Keywords: Marxist Dependecy Theory. Neoliberalism. Austericide. Brazil. 


\section{Introdução}

E $\mathrm{m}$ tempos de uma longa e profunda crise estrutural do Capital, esse que opera em uma "racionalidade irracional" (HARVEY, 2018) para manter e ampliar a sua taxa de lucro, impõe-se ao conjunto dos trabalhadores do mundo a barbárie da austeridade fiscal, com direitos sociais, trabalhistas e democráticos sendo cerceados de forma desigual e combinada pelo mundo, provocando o que passaremos a denominar "austericídio"1. Diante dos desafios societários que a conjuntura coloca àqueles que pensam na perspectiva não apenas de apreensão da realidade, mas também de sua transformação, a teoria e o método marxista se apresentam como um potente instrumento de análise.

Dado o caráter desigual e combinado do desenvolvimento capitalista (TROTSKY, 1967), a dialética relação entre as leis gerais de reprodução do capital mundializado e as expressões particulares das economias dependentes, a Teoria Marxista da Dependência (TMD) se propõe a avançar na investigação do capitalismo, em especial, na América Latina.

Desenvolvemos, na primeira sessão, a partir do arsenal teórico marxiano, as categorias estruturantes da TMD, a saber: Dependência, Superexploração, Transferência Desigual e Cisão entre Produção e Circulação. $\mathrm{Na}$ sessão seguinte, articulamos tais elementos no contexto de reestruturação produtiva e financeirização da economia latino-americana, com o exemplo do Chile, no qual foi inaugurada pela ditadura de Pinochet, a imposição do regime de capitalização previdenciária, que inspira a proposta de "Nova Previdência" no Brasil. Por fim analisaremos as expressões da crise política, social e econômica no Brasil, que vive atualmente um processo de "reversão neocolonial" (SAMPAIO JR., 2017): a reprimarização da economia, a desindustrialização, a privação de soberania sobre recursos naturais, a preponderância do capital rentista e uma série de retrocessos em direitos sociais e trabalhistas, com destaque para reforma Trabalhista e da Previdência.

\section{A Teoria Marxista da Dependência: conceitos e fundamentos}

A Teoria Marxista da Dependência é um desdobramento da teoria do valor em Marx e da teoria do Imperialismo em Lênin (LUCE, 2018) para compreensão da formação sócio-histórica das economias dependentes na dinâmica internacional do capital. Essa concepção foi desenvolvida por autores brasileiros e latino americanos ao longo das décadas de 1960 e 1970, Dentre os quais destacam-se: Rui Mauro Marini, Vânia Bambirra e Theotônio dos Santos, além de outros intelectuais e militantes socialistas deste período². Esta formulação teórica, que engloba as três fontes do marxismo (filosofia, economia e política) rompe ao mesmo tempo com o pensamento nacional-desenvolvimentista, então influente na comissão Econômica para a América Latina e o Caribe $\left(\mathrm{CEPAL}^{3}\right)$; como também procura superar uma visão marxista dogmática e "etapista"4 (portanto, não dialética), que classificava países como o Brasil como semifeudal.

À medida que as relações capitalistas de produção se impõem e se mundializam, também se particularizam em cada formação sócio-histórica, bem como suas expressões da questão social. Dentro dessa totalidade se expressam novas contradições e mediações. No caso latino-americano e brasileiro, uma vez emancipado do caráter formal de colônias, prosseguiu a subsunção real destas economias às potências centrais e à dinâmica internacional do Capital (MARINI, 2000), preservando-se o caráter dependente.

Para Gunder Frank (1967) o subdesenvolvimento dos países da América Latina se dava, justamente determinado pelo desenvolvimento do capitalismo mundial, e não pela falta ou por uma deformação dele, posto que o subdesenvolvimento e a dependência são funcionais à própria dinâmica central do capital.

Para contrarrestar o caráter desigual na concorrência do mercado externo, a acumulação capitalista dependente lança mão do expediente da superexploração da força de trabalho, considerada por Osório (2012) o principal fundamento da dependência, como a violação do valor da força de trabalho, não se apropriando apenas do trabalho excedente, mas de parte do fundo de consumo e de vida do trabalhador (MARINI, 2000). Assim, descreve o autor: 
São negadas ao trabalhador as condições necessárias para repor o desgaste de sua força de trabalho: [...] porque lhe é obrigado um dispêndio de força de trabalho superior ao que deveria proporcionar normalmente, provocando assim seu esgotamento prematuro [...] é retirada inclusive a possibilidade de consumo do estritamente indispensável para conservar sua força de trabalho em estado normal. Em termos capitalistas, esses mecanismos (que ademais podem se apresentar, e normalmente se apresentam, de forma combinada) significam que o trabalho é remunerado abaixo de seu valor (MARINI 2000, p. 13).

Compromete-se, dessa forma, a corporeidade físico-psíquica do trabalhador sem a garantia do valor histórico-moral ${ }^{5}$ da reprodução da força de trabalho (LUCE, 2018). A superexploração do trabalho, é a característica determinante das economias dependentes e, no caso do Brasil, a superexploração, assim como o apassivamento das lutas sociais (seja via repressão ou cooptação), são as principais particularidades da questão social na formação sócio-histórica do capitalismo brasileiro (SANTOS, 2008). Marini acrescenta o seguinte papel à superexploração:

A superexploração é melhor definida pela maior exploração da força física do trabalhador, em contraposição à exploração resultante do aumento de sua produtividade, e tende normalmente a se expressar no fato de que a força de trabalho se remunera abaixo de seu valor real (MARINI, 2000, p. 13).

A superexploração incide de forma mais intensa que a exploração capitalista de modo geral, incidindo tanto na taxa de mais-valia absoluta e relativa. A burguesia dependente, buscando atenuar o atraso técnico na produtividade, com a aumento da intensidade da jornada e com "a redução de custos", não se limita a remunerar abaixo do valor da força de trabalho, mas sequer garante o valor dos bens de reposição da força de trabalho no que diz respeito ao dispêndio físico-psíquico, como também ao dispêndio do tempo de vida laboral e de vida total.

Neste sentido, as economias dependentes, em especial, as latino-americanas, são utilizadas pela divisão internacional do trabalho no abastecimento das economias centrais com produtos primários do setor agromineiro-exportador, as chamadas commodities.

Tais produtos são utilizados para fabricar meios de produção e mercadorias manufaturadas e, posteriormente, importados pelas economias periféricas. Deve-se ainda ressaltar que, principalmente no caso dos produtos agrícolas, tratando-se de gêneros alimentícios, componentes do chamado valor "histórico-moral" da força de trabalho, tais produtos produzidos e barateados pelas economias dependentes levam à desvalorização real da força de trabalho nos países centrais, portanto ampliam a mais-valia relativa $^{6}$ extraída (MARINI, 2000). Pode-se, então, inferir que a superexploração da força de trabalho apresenta aspectos prejudiciais, tanto para os trabalhadores das economias dependentes, quanto das centrais.

Mesmo com a modernização capitalista industrial, ao longo do século XX nos países periféricos, perdurou a dependência e o atraso tecnológico, submetidas ao pagamento de royalties às potências centrais, sem condições de concorrer no mercado mundial com a mesma produtividade e lucratividade. Com a economia centrada nestas exportações de produtos primários identifica-se uma das características das economias dependentes, o intercâmbio desigual:

Transações entre nações que trocam distintas classes de mercadorias, como manufaturas e matérias primas - o mero fato de que umas produzam bens que as outras não produzem, ou não o fazem com a mesma facilidade, permite que as primeiras iludam a lei do valor, isto é, vendam seus produtos a preços superiores a seu valor, configurando assim uma troca desigual (MARINI, 2000, p. 11).

Dessa forma, é "violada" a lei do valor (OSORIO, 2012), ela não é expressa da mesma maneira ao longo do desenvolvimento do modo de produção capitalista. Nesse processo de troca, as mercadorias 
manufaturadas com altos níveis tecnológicos são vendidas a preço "acima" do valor, o que pode ser identificado como a transferência de valor da economia dependente para a economia central.

Verifica-se, portanto, que há nações desfavorecidas que passam a ceder "gratuitamente" parte do valor produzido em suas economias, apesar da maior produtividade obtida nas economias centrais, cujo efeito em condições normais seria a redução do valor individual (MARINI, 2000). Observa-se, no entanto, o contrário: o preço praticado é superior ao valor. As economias dependentes, para contrarrestar tal tendência, buscam equiparar a balança comercial por meio do aumento da exploração da força de trabalho, com o prolongamento da jornada de trabalho e a supressão de conquistas sociais dos trabalhadores, por exemplo.

Marini (2000), observa também que, devido ao caráter exportador das economias latino-americanas, ocorre a cisão entre produção e circulação no ciclo do capital. Assim as matérias-primas produzidas pelas economias dependentes têm a etapa da circulação realizada no mercado externo, sendo as necessidades produtivas divorciadas da necessidade social de consumo da população local, como desenvolve o autor:

\begin{abstract}
a formação do mercado interno representa a contrapartida da acumulação de capital: ao separar o produtor dos meios de produção, o capital não só criou o assalariado, isto é, o trabalhador que só dispõe de sua força de trabalho, como também criou o consumidor. De fato, os meios de subsistência do operário, antes produzidos diretamente por ele, são incorporados ao capital, como elemento material do capital variável, e só são restituídos ao trabalhador quando este compra seu valor baixo a forma de salário (MARINI, 2000, p. 20).
\end{abstract}

Diferentemente das economias centrais onde a classe trabalhadora viveu o contexto de "bem-estar social" com pleno emprego da força de trabalho e amplos investimentos em políticas públicas e "salários indiretos", favorecendo o consumo de massas, nas economias dependentes, como o capital se realiza na exportação, não há interesse nessas garantias para os trabalhadores e o consumo é estratificado. Nessas, a maioria dos trabalhadores consomem apenas os bens necessários à sua já precária reprodução; há um mercado de bens suntuários importados para aqueles que podem pagar (OURIQUES; PAIVA, 2006). Nestas economias acirram-se as desigualdades sociais, inclusive, direitos sociais básicos, como transporte, educação, saúde e previdência social, tornam-se mercadorias de luxo para uma parcela minoritária da população que pode consumi-los. Simultaneamente a precariedade é intencionalmente generalizada nos serviços públicos estatais, a fim de transformar direitos sociais em mercadoria.

Essas tendências se acirram com a reestruturação produtiva neoliberal, com a consequente precarização dos direitos e das condições de trabalho em todo o mundo, aliados com elevadas taxas de desemprego e subemprego.

\title{
2 A contrarrevolução neoliberal nas economias dependentes
}

Um importante aspecto a se considerar na atualidade como forma de reproduzir a dinâmica de dependência são as "dívidas públicas", que passam a ser importantes instrumentos de subordinação dos Estados nacionais e de transferência de valor para o capital rentista globalizado. Pode-se afirmar que a América Latina passou por longos períodos de endividamento público, desde o século XIX, com as "independências formais" das metrópoles ibéricas, contraindo dívidas com o imperialismo britânico, e no século posterior sendo explorados pelo imperialismo estadunidense.

Um dos principais marcos históricos, foi o dia 19 de agosto de 1971, quando o presidente norteamericano Richard Nixon determinou a quebra do parâmetro ouro-dólar, estabelecido até então pela conferência de Breton Woods (MELCHIONNA, 2012). Foi aberta uma Caixa de Pandora, desencadeando a completa desregulamentação monetária e financeira de caráter abstrato e fetichizado, permitindo uma maior flexibilidade para atender às demandas de emissão de moeda norte-americana. 
A dinâmica da financeirização do Capital maturou-se com a crise do petróleo no final da década de 1970. Decididamente, neste momento, o modelo keynesiano-fordista começou a dar lugar ao neoliberalismo 8 e nas economias centrais (Europa, principalmente) não foi mais possível "abafar" as contradições do capitalismo, nem manter concessões à classe trabalhadora. $\mathrm{O}$ capital rearticulou-se para retomar as suas taxas de lucro, a custo da parte do produto social e do fundo público conquistado pelos trabalhadores, no caso das economias dependentes, com o uso da força.

Iniciou-se, então, a era da Acumulação Flexível (HARVEY, 1992), que estabeleceu novos padrões de produção, de acumulação, de consumo e de relações de trabalho. O momento contou com a completa fusão do capital produtivo e bancário, convertendo-se em capital financeiro (também conhecido como portador de juros ou fictício). Essa hegemonia do capital portador de juros não dispensa a necessidade do trabalho produtivo, mas de forma articulada impõe novas dinâmicas à produção: flexibilizando (via de regra precarizando) as relações e condições de trabalho ao transpor para a produção real a exigência, de que cada empresa obtenha a rentabilidade média aplicada pelos acionistas (LEITE, 2010). A superexploração nesse sentido, consolida a sua característica: deixa de ser um fenômeno exclusivo das economias dependentes, ao se mundializar e se agudizar com a própria globalização das finanças (SOTELO VALENCIA, 2009).

Segundo Chesnais (2005), neste cenário ganham espaço os fundos de pensão, que transformam a poupança dos assalariados para aposentadoria em ativos para investimentos de risco, sendo extremamente beneficiados com a liberalização financeira.

O principal laboratório desta política foi o Chile, justamente uma economia dependente latinoamericana, em plena ditadura empresarial-militar de Augusto Pinochet. Esse foi o primeiro país, instruído pela vertente da "Escola de Chicago", a impor a migração do regime de repartição solidária para a capitalização individual, muito lucrativo para os fundos de pensão, mas completamente instável e inseguro para o contribuinte, pois a contribuição é prefixada, porém o benefício-valor auferido fica à mercê das flutuações do mercado, destituindo-se o caráter de direito social.

Nesta realidade, o capital financeiro mundializado clama, não apenas de pelo suor de milhões de trabalhadores superexplorados, seja nas minas de cobre, seja na vinicultura (principais produtos de exportação chilenos), mas pela vida digna futura na aposentadoria. Atualmente no Chile, os aposentados por esse regime vivem em média com menos de um terço do salário mínimo daquele país, com elevados índices de suicídio entre idosos.

Neste cenário, órgãos como o Banco Mundial e o Fundo Monetário Internacional passaram a "recomendar" aos países (principalmente os dependentes) a reestruturações nas políticas previdenciárias alegando a inviabilidade financeira e atuarial desses programas devido à tendência demográfica, e garantia da estabilidade fiscal, conforme o relatório "Envelhecimento sem Crise" (BANCO MUNDIAL,1994).

A hegemonia financeira também reproduz seus capitais nos serviços de dívida pública, ou mercado de obrigações (CHESNAIS, 2005) principalmente com a compra de títulos da dívida de países periféricos, que para saldar os juros, contraem novos empréstimos. Processo este que reproduz a especulação rentista, mantendo a subordinação econômica e política destas nações. O Estado, por sua vez, reafirma seu papel de "comitê gestor" de interesses burgueses, para remunerar estes capitais através de títulos da dívida pública e "flexibiliza" legislações e direitos trabalhistas e previdenciários para reduzir o custo da produção, garantindo a reprodução ampliada e a superexploração do trabalho. A acumulação flexível é a estratégia adotada para reorganizar a extração de mais-valia.

\subsection{O "ajuste fiscal permanente": o caso brasileiro}

O Brasil, apesar de ser a principal economia em seu continente, mantém as características elencadas das economias dependentes. A herança colonial e escravocrata é fundante da formação sócio-histórica da sociedade burguesa no País. Uma vez atingida, a sua independência formal manteve uma posição dependente no capitalismo mundial. Ao longo da sua modernização burguesa manteve um padrão centrado no modelo agromineiro-exportador. 
Historicamente manteve-se um padrão muito baixo de valorização da força de trabalho (FERNANDES, 2004), mesmo após a abolição da escravatura e da proclamação da República, sem mudanças estruturais na propriedade fundiária nem nas relações de poder.

Em que pese os direitos conquistados pela população, que furaram o bloqueio das oligarquias políticas e econômicas, ao longo da história a burguesia nacional sempre buscou a transição lenta, gradual e superestrutural, sem colocar em xeque os seus privilégios, alheia aos anseios populares, realizando "revoluções passivas" (FERNANDES, 2004).

Mesmo com avanços na Constituinte de 1988 - fruto da mobilização popular da redemocratização -, o processo ficou inacabado (FERNANDES,1988), com uma série de temas "em aberto" a serem regulamentados por leis complementares e emendas constitucionais, permitindo a desfiguração do caráter "cidadão" da Carta Magna, apesar da mesma prever reformas como a agrária, urbana e tributária. Pode-se afirmar que tais medidas foram inviabilizadas por opção política dos governantes e das aristocracias financeiras, sem permitir a concretização de mudanças nas estruturas de poder político e econômico.

Enquanto a lei previa uma série de políticas de proteção social, os vários governos inviabilizaram o cumprimento das políticas previstas, principalmente aquelas previstas para a Seguridade Social. Desta forma, recorreu-se novamente ao caminho da "contrarrevolução preventiva, evitando que o País transitasse para uma experiência sequer de Estado de Bem-Estar Social duradouro e a Previdência, um dos principais alvos desta batalha do capital rentista, se arrastou desde o princípio da Nova República até seu desmoronamento nos dias atuais" (CORREA, 2019).

Pode-se dizer que na conduta política brasileira do período recente desenvolveu-se ao longo da República um processo de "ajuste fiscal permanente" que pode ser analisado em três fases: a fase neoliberal ortodoxa (década de 1990), a fase social-liberal ou neodesenvolvimentista (2002-2016), e a fase da retomada da ortodoxia neoliberal (2016 até hoje). Ao longo dos dias atuais uma série de medidas governamentais retrocederam em direitos sociais, em oposição ao programa constitucional.

Na primeira fase, foram dadas as bases da contrarreforma neoliberal do Estado, que envolve os governos Collor e Fernando Henrique Cardoso (FHC) cujo formulador foi Bresser-Pereira, então ministro da Reforma do Estado (MARE), obedecendo recomendações do chamado "Consenso de Washington". O chamado tripé macroeconômico ${ }^{9}$ assumiu o papel de diretriz: sob a égide de redução máxima das despesas (sociais) do Estado, priorizando poupar recursos para o pagamento do serviço financeiros da dívida pública, favorecendo com isto, sobremaneira, a elite rentista.

Cumprindo os receituários de órgão internacionais, ocorreu uma reestruturação gerencialista do Estado, uma série de privatizações e terceirizações em órgãos públicos, fator previdenciário e regulamentação de fundos de pensão ${ }^{10}$, bem como medidas de superávit fiscal ${ }^{11}$.

Em 2002, depois de um desgaste do modelo neoliberal ortodoxo, elegeu-se Luiz Inácio Lula da Silva para a Presidência da República, que estabeleceu um governo de conciliação de classes. O social-liberalismo preservou os fundamentos macroeconômicos dos governos anteriores e, reforçando a hegemonia dos capitais financeiros, preservou a estrutura fundiária concentrada e ofereceu incentivo aos fundos privados de pensão (ANTUNES, 2013).

Mesmo com uma política de expansão de programas sociais e valorização do salário mínimo, aquecendo o consumo de massas, deu início a uma nova Contrarreforma da Previdência ${ }^{12}$, concessão de portos e aeroportos para a iniciativa privada, além da manutenção da DRU e da LRF e a elevação da taxa de juros (MOTA, 2012).

Após quatorze anos do ciclo social-liberal, com o aprofundamento da crise econômica global, o governo de Dilma Rousseff, incapaz de atender com celeridade à demanda rentista, em 2016 sofreu um golpe parlamentar que destituiu a Presidenta. Inicia-se, então, a terceira fase do ajuste fiscal com a retomada de forma explícita à ortodoxia neoliberal, com retrocessos históricos em direitos trabalhistas e sociais.

Esse ajuste, ainda mais severo, limita ainda mais a soberania nacional sobre as riquezas naturais e os produtos do setor agromineiro, como aprofundamento das relações de troca desigual de produtos primários, como o petróleo, os minérios, as carnes, o açúcar, o café, a sojas e os grãos. (PAIVA et al., 2018). Destacam 
as autoras que, sobretudo, como economia dependente, para além da abundância natural, destaca-se a espoliação da verdadeira força produtora de riqueza, que é a força de trabalho.

Para extrair ainda mais riqueza da massa de trabalhadores, entidades patronais já defendiam a necessidade de novas contrarreformas, em especial três âmbitos: Orçamento Público, Direitos Trabalhistas e a Previdência Social. Essas medidas, articuladas entre si, compõem o atual receituário da austeridade no Brasil dependente, com a ampliação da superexploração, a extinção do Estado social e a inviabilidade do desenvolvimento não dependente e não financeirizado. Esse programa é executado pelo Governo ilegítimo de Michel Temer e continuado, atualmente, no governo de Jair Bolsonaro.

Em 2016 foi aprovada a Emenda 95, que instituiu o “Novo Regime Fiscal” (NRF), que proíbe qualquer reajuste real às despesas não financeiras nos próximos vinte anos, inviabilizando a vinculação constitucional dos recursos para as políticas sociais. Essa medida aprofunda os efeitos nocivos da LRF, não afetando despesas financeiras destinadas ao rentismo, que consome $40 \%$ do Orçamento da União (AUDITORIA CIDADÃ, 2018). Em 2017, a DRU foi prorrogada até 2023 e aumentada a sua alíquota para 30\%, desidratando recursos destinados às políticas de seguridade social, ao mesmo tempo que mascara a necessidade de reforma da previdência.

Com a crise estrutural e o crescimento do desemprego, foi apresentada também em 2017, a Reforma Trabalhista, outra contrarreforma que restringe direitos e precariza ainda mais as condições de vida e trabalho. A Lei no 13.467/2017, modifica mais de 100 artigos da Consolidação das Leis Trabalhistas (CLT), na qual observa-se uma série de consequências nefastas que autorizaram a realização de contratos precários sob a justificativa de combater a informalidade (TEIXEIRA, 2018). No texto, abre-se precedente para demissões em massa, regime intermitente e o princípio "negociado sobre o legislado". Essa perspectiva individualiza as relações capital-trabalho, pois autoriza que o trabalhador individual "negocie" de forma ainda mais assimétrica e instável com o patrão sobre suas condições de trabalho (férias, intervalo de almoço, jornada de trabalho).

Tal legislação permite a retirada de cena dos sindicatos, bem como do próprio aparelho de Estado, por meio da Justiça do Trabalho e do já extinto Ministério do Trabalho. Essa suposta "modernização" das relações de trabalho, promete que, ao reduzir os custos do empregador, trará mais contratações, sob as condições por ele impostas. No entanto, observa-se que tal afirmativa não é verdadeira já que o Brasil se encontra atualmente com mais de 13 milhões de desempregados (IBGE, 2019), somados aos trabalhadores informais, totalizando aproximadamente $25 \%$ de subutilização da força de trabalho.

Essas medidas, junto à ampliação das terceirizações aprofundam a superexploração que já é regra no País. Tal fenômeno se acirra com o processo de desindustrialização das últimas décadas, com os recentes fechamentos de grandes montadoras, que levam a um novo ciclo vicioso de demissões e recessão econômica, retomando o perfil de economia dependente que vive um processo de reversão neocolonial (SAMPAIO JR., 2017). É retomado o perfil agromineiro-exportador, com menos direitos sociais e liberdades democráticas aos trabalhadores.

Outra consequência do crescimento do desemprego e da informalidade é a diminuição do número de contribuintes, logo, de segurados pela seguridade social, que já é alvo do capital rentista. Se não bastassem a desproteção das relações de trabalhistas e previdenciárias, evidencia-se que o próprio Estado brasileiro incentiva a desformalização das relações de trabalho, enquanto justifica uma nova contrarreforma da previdência, concretizando, dessa forma, uma contrarrevolução neoliberal, levando a austeridade fiscal a um patamar de "austericídio", ao submeter milhões de trabalhadores à completa barbárie do capital, superexploração, miséria, morte.

Novamente, os interesses dos fundos de pensão se voltam para a Previdência Social, terceiro item da desconstitucionalização neoliberal. Houve, em 2017, mais uma tentativa de aprovação de nova Reforma da Previdência, com imposição de idade mínima de 65 anos e 49 anos de contribuição, que foi motivo de ampla rejeição e resistência da população, cujo ápice foi a Greve Geral de 2017, fato que impediu a apreciação do projeto.

Em 2018, em uma conjuntura ainda mais conturbada e polarizada elegeu-se presidente Jair Bolsonaro. Sua equipe econômica, chefiada por Paulo Guedes, retoma a reforma da Previdência como pauta prioritária, 
dando continuidade ao "ajuste fiscal permanente" que vem sendo aplicado. A Proposta de Emenda à Constituição no 6 (BRASIL, 2019) incorpora elementos do projeto do governo anterior, sob a falsa narrativa de combate a "privilégios" e "correção de déficit", na qual, mesmo ainda sendo um projeto de lei, é possível identificar inúmeros retrocessos contra camadas vulneráveis da população.

Assim como as outras reformas, busca-se, entre outras medidas, protelar o tempo para fazer jus ao benefício da aposentadoria, com a exigência de 65 anos para homens e 62 para mulheres, combinada com 40 anos de contribuição para obter a média máxima de benefício. A exigência combinada de idade e tempo de contribuição dificulta o acesso ao direito devido à crescente informalidade, reduzindo o montante de contribuições e dificultando o cumprimento do requisito de tempo, principalmente para os trabalhadores mais precarizados, que costumam ingressar no mercado de trabalho mais jovens. No caso das mulheres o retrocesso é mais gritante, já que não é considerado o desgaste desigual da dupla ou tripla jornada vividas pelas trabalhadoras. A reforma também ataca os trabalhadores rurais e professores, que terão exigência de 60 anos de idade e a elevação para 20 e 30 anos de contribuição, respectivamente.

A Reforma reduz o acesso aos benefícios socioassistenciais para idosos e pessoas com deficiência em condição de miserabilidade, elevando de 65 para 70 anos a idade mínima para percepção do BPC (Benefício de Prestação Continuada) de um salário mínimo, e oferece o valor de 400 reais (menos da metade do salário mínimo) para maiores de 60 anos.

Nenhuma destas medidas é necessária para "salvar" a economia nacional ou combater "privilégios" de trabalhadores. Já que considerando-se dados fidedignos como da Anfip (2016), deduzidas as renúncias fiscais e a desvinculação da receita da união (DRU) há um significativo superávit, sendo possível ampliar os serviços em saúde, assistência social e previdência social (SALVADOR, 2017). Ainda nesse sentido, a CPI da Previdência (BRASIL, 2018) levou a público que grandes empresas somam mais 450 bilhões em dívidas para a Seguridade Social.

No entanto, desde a Nova República todas as medidas governamentais foram destinadas a negar o acesso ao direito social. Por isso, constitui-se uma escolha política do Estado brasileiro de desmontar as políticas públicas conquistadas e criar mecanismos para inviabilizar a realização dos direitos sociais.

Além disso, está em risco o próprio modelo solidário de seguridade social. A reforma autoriza a transição para a capitalização. No caso brasileiro, caso tal medida se concretize, completa-se o ciclo de desmonte do caráter social e público do sistema previdenciário, responsabilizando-se cada indivíduo pela composição do seu fundo de aposentadoria e garantindo altos lucros para o capital fictício. A proposta de emenda não detalha o seu funcionamento, mas prevê regulamentação em lei complementar, de mais fácil aprovação no legislativo. A proposta tornaria o regime individual compulsório, no qual o trabalhador seria "livre" para escolher o banco (público ou privado) bem como a rentabilidade (e o risco) ao aplicar o seu dinheiro. Rompe-se, dessa forma, a garantia da segurança social do recurso entesourado para a situação de aposentadoria.

\section{Considerações finais}

Considerando o cenário anteriormente exposto, conclui-se que a Teoria Marxista da Dependência nos permite constituir elementos para aprofundar a análise de como se manifesta a crise estrutural do capital no Brasil e na América Latina. A condição dependente leva a três consequências políticas principais (LUCE, 2018): uma limitada soberania nacional, uma exploração redobrada da força de trabalho e, um Estado democrático mais restrito, já que as necessidades da economia agroexportadora não contemplam a produção socialmente necessária para a maioria da população trabalhadora, nem convém amplas liberdades democráticas ou direitos sociais. Não é por acaso que tais economias apresentam elevados índices de desigualdade social e, mesmo o Brasil sendo a principal economia da região, verificam-se crescentes índices de desigualdade.

$\mathrm{Na}$ atualidade o projeto austericida, já atinge inclusive economias centrais europeias, mas foi nas economias dependentes, que o capital necessitou de um "banho de sangue" operado por ditaduras militares em toda América do Sul (sendo o caso já citado do Chile o mais emblemático do extremo-liberalismo). 
Atualmente, a tragédia se repete em outros países, e bate à porta do Brasil. A capitalização como modelo previdenciário ameaça os trabalhadores do passado, do presente e do futuro, de forma parasitária, rompendo os laços solidários intergeracionais, pois os já aposentados não têm a garantia da contribuição dos atuais trabalhadores. Esses que vão buscar os empregos em piores condições para cumprir o tempo de contribuição cada vez mais longínquo, sequer terão perspectiva de alguma segurança social. Em última instância, o desejo do capital, além de explorar ao máximo a força de trabalho, é a morte desse trabalhador antes de atingir a idade não produtiva, podendo especular seu fundo de aposentadoria. A política do capital deixou de limitar-se a uma política de exclusão, para tornar-se em política de extermínio, sobretudo nos países dependentes.

Por outro lado, para haver um efetivo desenvolvimento autônomo e soberano na América Latina, é necessária a construção de uma perspectiva de superação da "racionalidade irracional" do capital e avançar para uma perspectiva societária socialista, sem a exploração, nem a opressão de classe gênero ou etnia (CFESS, 1992). A solução para essa encruzilhada histórica vai depender da correlação de forças entre as classes sociais, sendo que, o desenlace desta encruzilhada é uma questão que o tempo e, fundamentalmente a luta, dirão.

\section{Referências}

ANTUNES, Ricardo. Inglaterra e Brasil: duas rotas do social-liberalismo em duas notas currículo sem fronteiras, Currículo sem Fronteiras, [s. I.], v. 13, n. 2, p. 204-212, maio/ago. 2013.

ASSOCIAÇÃO NACIONAL DOS AUDITORES-FISCAIS DA RECEITA FEDERAL DO BRASIL/ANFIP. Fundação ANFIP de estudos tributários da seguridade social. Análise da seguridade social 2016. Brasília: ANFIP, 2017. https://doi. org/10.11606/d.2.2006.tde-19052010-110621

AUDITORIA CIDADÃ DA DÍVIDA. Números da dívida: Auditoria Cidadã da Dívida. Brasília, 2019. Disponível em: http://www.auditoriacidada.org.br/blog/2013/08/30/numeros-da-divida/. Acesso em: 3 fev. 2019 https://doi.org/ 10.30620/p.i..v7i2.4502

BANCO MUNDIAL. Envejecimentos sin crisis: políticas para la proteccíon de los ancianos y la promoción del crescimiento. Washington: Banco Mundial, 1994. Disponível em: http://www.redalyc.org/articulo.oa?id=10638617. Acesso em: 1 nov. 2018. https://doi.org/10.1596/978-9-5883-0787-9

BRASIL. [Constituição Federal (1988)]. Brasília, DF, out. 1988.

BRASIL. Lei no 13.467, de 13 de julho de 2017. Institui a Reforma Trabalhista. Diário Oficial da União: seção 1, Brasília, DF, n. 2.200-2 de 24/08/2001, p. 63, jul. 2017. Portaria no 889. http://dx.doi.org/10.22420/rde.v11i20.774

BRASIL. Proposta de Emenda à Constituição n. 06/2019: Modifica o sistema de previdência social, estabelece regras de transição e disposições transitórias, e dá outras providências. Disponível em: https://www.camara.leg.br/ proposicoesWeb/fichadetramitacao?idProposicao=2192459. Acesso em: 02 set. 2019.

CONSELHO FEDERAL DE SERVIÇO SOCIAL - CFESS (Brasil). Código de Ética Profissional dos Assistentes Sociais. Brasília, DF, 1993.

BRESSER-PEREIRA, Luiz Carlos. O governo Dilma frente ao "tripé macroeconômico" e à direita liberal e dependente. Novos estudos CEBRAP, São Paulo, n. 95, p. 5-15, mar. 2013. Disponível em: http://www.scielo.br/pdf/nec/n95/01.pdf. Acesso em: 15 mar. 2018. https://doi.org/10.1590/s0101-33002013000100001

CHESNAIS, F. O Capital portador de juros: acumulação, internacionalização efeitos econômicos e políticos. In: CHESNAIS, F. (org.). A finança mundializada: raízes sociais e política, configuração e consequências. São Paulo: Boitempo, 2005.

CORREA, B. Simulacro de aprendizagem e precarização do trabalho: dimensões da utilização dos estágios não-obrigatórios no Rio Grande do Sul em tempos de acumulação flexível. 2009. 78 f. Monografia - Instituto de Filosofia e Ciências Humanas, Universidade Federal do Rio Grande do Sul, Porto Alegre, 2009. https://doi. org/10.29289/259453942018v28s1059 
CORREA, B. A Importância Histórica Da Batalha Pela Previdência Social. Movimento: crítica, teoria e ação, [São Paulo], mar. 2019. Disponível em: https://movimentorevista.com.br/2019/03/a-importancia-historica-da-batalha-pelaprevidencia-social/. Acesso em: mar. 2019.

DEPARTAMENTO INTERSINDICAL DE ESTUDOS SÓCIO-ECONÔMICOS - DIESSE. Salário Mínimo. São Paulo: DIEESE, [2017]. Disponível em: https://www.dieese.org.br/analisecestabasica/salarioMinimo.html. Acesso em: nov. 2018. http://dx.doi. org/10.1590/S0102-88392002000300008

FERNANDES, Florestan. Processo constituinte. Brasília: Câmara dos Deputados, 1988. (Separatas de discursos, pareceres e projetos. 48a Legislatura. 2a Sessão Legislativa, 26).

FERNANDES, Florestan. In: IANNI, Otávio (org.). Florestan Fernandes: sociologia crítica e militante. São Paulo: Expressão popular, 2004.

FERREIRA, Carla; OSORIO, Jaime; LUCE, Mathias. Padrão de reprodução do capital: contribuições da teoria marxista da dependência. São Paulo: Boitempo, 2012.

GUNDER FRANK, Andre. America Latina: subdesarrollo o revolución. Mexico: Ediciones Era, 1973.

HARVEY, D. A Loucura da Razão Econômica. São Paulo; Boitempo, 2018.

IAMAMOTO, Marilda Villela. Serviço Social em tempo de capital fetiche: capital financeiro, trabalho e questão social. 2. ed. São Paulo: Cortez, 2008. https://doi.org/10.5433/1679-4842.2018v21n1p183

INSTITUTO BRASILEIRO DE GEOGRAFIA E ESTATístICA. Pesquisa Mensal de Emprego: Série Histórica. [S. I.]: IBGE, [2017?]. Disponível em: https://ww2.ibge.gov.br/home/estatistica/indicadores/trabalhoerendimento/pme/pmemet2.shtm. Acesso em: mar. 2019. https://doi.org/10.17143/ciaed/xxiilciaed.2017.00322

LEITE, M. G. O Processo de Financeirização do Segmento da Previdência Complementar Privada. In: MARQUES, R.; FERREIRA, M. (org). O Brasil sob a nova ordem: a economia brasileira contemporânea: uma análise dos governos Collor a Lula. São Paulo: Saraiva, 2010.

LUCE, Mathias. Teoria marxista da dependência: problemas e categorias; uma visão histórica. São Paulo: Expressão Popular, 2018.

MARINI, Ruy Mauro. Dialética da dependência. Petrópolis: Vozes, 2000.

MARX, Karl. O capital: crítica da economia política. São Paulo: Boitempo, 2013.

MELCHIONNA, Fernanda. Fundos de pensão diante da mundialização financeira: o caso da previ entre 2003 a 2010. 2012. 79 f. Trabalho de conclusão de curso (Especialização) - Faculdade de Porto Alegre/FAPA, Porto Alegre, 2012. https://doi.org/10.22456/2177-0018.87833

MOTA, Ana E. Redução da pobreza e aumento da desigualdade: um desafio teórico político para o serviço social brasileiro. In: Ana Elizabete (org.). Desenvolvimentismo e construção de hegemonia: crescimento econômico e reprodução da desigualdade. São Paulo: Cortez, 2012. p. 29-45.

PAIVA, Beatriz; OURIQUES, Nildo. Uma perspectiva latino-america-na para as políticas sociais: quão distante está o horizonte? Katálysis, Florianópolis, v. 9, n. 2, p. 166-175, 2006. Disponível em: http://www.scielo.br/pdf/rk/v9n2/ a04v09n2. Acesso em: 10 mar. 2018. https://doi.org/10.1590/s1414-49802006000200004

SALVADOR, Evilasio. O desmonte do financiamento da seguridade social em contexto de ajuste fiscal. Serviço Social e Sociedade, São Paulo, n. 130, p. 426-446, set./dez. 2017. Disponível em: http://www.scielo.br/pdf/sssoc/n130/0101-6628sssoc-130-0426.pdf. Acesso em: 2 nov. 2017. https://doi.org/10.1590/0101-6628.117

SAMPAIO Jr., Plínio de Arruda. Crônica da Crise Anunciada. São Paulo: SG-Amarante, 2017.

SANTOS, J. S. Particularidades da "questão social" no capitalismo brasileiro. 2008. 222 f. Tese (Doutorado) - Escola de Serviço Social da Universidade Federal do Rio de Janeiro, 2008. https://doi.org/10.5753/ersirj.2018.4649

SENADO FEDERAL. Agência Senado (Brasil.) Empresas privadas devem R\$ 450 bilhões à Previdência, mostra relatório final da CPI. Da redação, Brasília, 23 out. 2017. Disponível em: https://www12.senado.leg.br/noticias/materias/2017/10/23/ empresas-privadas-devem-r-450-bilhoes-a-previdencia-mostra-relatorio-final-da-cpi. Acesso em: nov 2018. 
SOTELO VALENCIA, Adrián. A reestruturação do mundo do trabalho: superexploração e novos paradigmas da organização do trabalho. Uberlândia: EDUFU, 2009. https://doi.org/10.14393/edufu-978-85-7078-226-7

TEIXEIRA, Etevaldo. A reforma trabalhista após 6 meses. Movimento: crítica, teoria e ação. [São Paulo], jun. 2018.

Disponível em: https://movimentorevista.com.br/2018/06/a-reforma-trabalhista-apos-seis-meses/. Acesso em: mar. 2019.

TROTSKY, Leon. A história da revolução russa. Rio de Janeiro: Saga, 1967.

\section{Notas}

${ }^{1}$ Utilizaremos ao longo deste artigo o termo austericídio para se referir ao genocídio estrutural dos trabalhadores provocado pelas políticas de austeridade neoliberal, que rompe com mínimos padrões de civilidade conquistados pelas classes "subalternas".

2 Os três citados chegaram a participar da Organização Revolucionária Marxista Política Operária (POLOP), organização leninista dos anos 1960, foram exilados e ativos combatentes das ditaduras do Conesul.

${ }^{3}$ Esta entidade adota uma concepção nacional-desenvolvimentista caracterizada pela aceitação das "etapas" de desenvolvimento nos países periféricos, que viriam a evoluir para o chamado "primeiro mundo".

${ }^{4}$ Desvio no pensamento marxista, recorrente na primeira metade do século XX, que considera à história do desenvolvimento capitalista de forma linear e considera que só é possível atingir o socialismo após o pleno desenvolvimento capitalista no país em questão.

${ }^{5}$ No caso brasileiro podemos mensurar este valor pelo "salário mínimo ideal" calculado pelo DIEESE, com base no cumprimento dos requisitos constitucionais (transporte, moradia, alimentação, lazer), para outubro de 2018 chega a um valor de $\mathrm{R} \$ 3.783,39$, enquanto o salário mínimo nominal é aproximadamente 4 vezes inferior. Seu montante atual é de R\$ 954 (DIEESE, 2018).

${ }^{6}$ A Mais-Valia Relativa, é o método de extração de valor independente do prolongamento da jornada de trabalho, com a redução do tempo de trabalho necessário, que pode ocorrer com o incremento da produtividade ou intensidade do trabalho, ou por meio da redução do custo de vida média dos trabalhadores, com redução do preço de alimentos e demais bens básicos (MARX, 2013).

7 Para Marx (2013) preço e valor não necessariamente coincidem. Ao longo do livro, como opção didática, o autor trata todas as transações como se fossem conforme o seu valor, porém em uma leitura de $\mathrm{O}$ Capital mais abrangente, podemos identificar situações em que as trocas não respeitam o Valor.

${ }^{8}$ Fundamentalmente o neoliberalismo significava um ambiente favorável aos negócios privados, uma hegemonia do capital financeiro associado ao capital produtivo, a privatização dos serviços públicos e a "diminuição" da atuação do Estado nas áreas sociais. [...] Os traços essenciais desta política são expressos na fórmula de "livre negociação" entre capital e trabalho e "livre comércio" entre os países (CORRÊA, 2009, p. 30).

${ }^{9}$ O tripé macroeconômico é acompanhado destas três medidas de política monetária: superávit primário, câmbio flutuante e meta de inflação (BRESSER-PEREIRA, 2013).

${ }^{10}$ A Emenda Constitucional no 20, de 15 de dezembro de 1998, foi a primeira medida a impor restrições à aposentadoria por tempo de contribuição e regulamenta os fundos de pensão, como "previdência complementar" (MELCHIONNA, 2012).

${ }^{11}$ Destaca-se a Desvinculação da Receita da União (DRU) que autoriza o desvio de recursos da seguridade social para outros fins; bem como a Lei de Responsabilidade Fiscal (LRF), que criminaliza o governante que investir mais do que arrecada em despesas não financeira. Todas vêm sendo usadas para preservar o superávit primário.

${ }^{12}$ Destaca-se as EC 41 e 43 de 2003 e 2005 que retrocedem principalmente em direitos dos servidores públicos, com o fim da integralidade e paridade, o teto de benefício, a exigência combinada de idade e tempo de contribuição, bem como a institucionalização do Funpresp.

Recebido em: 10/4/2019.

Aprovado em: 12/4/2019.

Publicado em: 10/10/2019.

\section{Correspondência para:}

Marcos Pereira Diligenti

Faculdade de Arquitetura e Urbanismo

Pontifícia Universidade Católica do Rio Grande do Sul (PUCRS)

Av. Ipiranga, 6681, prédio 9, sala 209 - Partenon

90619-900, Porto Alegre, RS, Brasil

\section{Autores:}

MARCos PeREIRA DILIGENTI

Doutor em Educação pela Universidade Federal do Rio Grande do Sul (UFRGS). Professor titular do curso de Arquitetura e Urbanismo (PUCRS) e Professor permanente do Programa de Pós-graduação em Serviço Social (PPGSS) da Pontifícia Universidade Católica do Rio Grande do Sul (PUCRS), Porto Alegre, RS, Brasil.

Orcid: https://orcid.org/0000-0003-1372-5791

E-mail: mdilig@pucrs.br

RICARDo SOUZa ARAUjo

Graduado em Serviço Social pela Universidade Federal do Rio Grande do Sul (UFRGS). Mestrando pelo Programa de Pós-Graduação em Serviço Social (PPGSS/PUCRS), Porto Alegre, RS, Brasil. Assistente em Administração, Universidade Federal do Rio Grande do Sul (UFRGS), Porto Alegre, RS, Brasil.

Orcid: https://orcid.org/0000-0003-1452-3323

E-mail: ricardo.toxza@gmail.com

Endereço: Universidade Federal do Rio Grande do Sul (UFRGS)

Campus do Vale - Agronomia - 91509900, Porto Alegre, RS, Brasil 